\title{
Delayed Reward Discounting
}

National Cancer Institute

\section{Source}

National Cancer Institute. Delayed Reward Discounting. NCI Thesaurus. Code C99494.

A form of impulsivity related to the increased perceived value of immediate gratification as compared to a larger future reward. The more remote the future reward, the lower its perceived present value (the more it is discounted) and the less likely it is to be chosen. 